\title{
Coordination of end-of-life care for patients with lung cancer and those with advanced COPD: are there transferable lessons? A longitudinal qualitative study
}

\author{
*Eleni Epiphaniou', Cathy Shipman', Richard Harding', Bruce Mason², Scott AA Murray², \\ Irene J Higginson', Barbara A Daveson'
}

1 Department of Palliative Care Policy and Rehabilitation, Cicely Saunders Institute, King's College London, London, UK
2 Primary Palliative Care Research Group, Centre for Population Health Sciences, University of Edinburgh, Edinburgh, UK

Originally received 19th July 2013; resubmitted 9th October 2013; revised 20th November 2013; accepted 3rd December 2013;

online 29th January 2014

\begin{abstract}
Background: Care coordination is defined as good communication between professionals to enable access to services based on need.

Aims: To explore patients' experience of care coordination in order to inform current debates on how best to coordinate care and deliver services in end-of-life for patients with lung cancer and those with chronic obstructive pulmonary disease (COPD).

Methods: A qualitative study involving serial interviews was performed in 18 patients recruited from three hospital outpatient clinics situated in a hospital. Interviews were transcribed verbatim and data were analysed thematically.

Results: Data comprised 38 interviews. Patients experiencing services related to lung cancer reported good access enabled by the involvement of a keyworker. This contrasted with COPD patients' experiences of services. The keyworker coordinated care between and within clinical settings, referred patients to community palliative care services, helped them with financial issues, and provided support.

Conclusions: For patients with lung cancer, the keyworker's role augmented access to various services and enabled care based on their needs. The experiences of patients with COPD highlight the importance of providing a keyworker for this group of patients in both secondary and primary care.

(C) 2014 Primary Care Respiratory Society UK. All rights reserved.

E Epiphaniou et al. Prim Care Respir J 2014; 23(1): 46-51

http://dx.doi.org/10.4104/pcrj.2014.00004
\end{abstract}

Keywords lung cancer, COPD, coordination, keyworker, qualitative research, palliative care, end-of-life care

See linked editorial by LeBlanc et al. on pg 8

\section{Introduction}

Palliative care aims to optimise the quality of life and provide holistic care for patients and their families. ${ }^{1}$ Historically, palliative care services have mainly been offered to patients with incurable cancer. ${ }^{2}$ Current perspectives encourage access to palliative care based on need rather than diagnosis, but this is still difficult to achieve. ${ }^{3}$ Patients with advanced progressive chronic obstructive pulmonary disease (COPD) have difficulties in accessing supportive and palliative care because the condition is characterised by a variable illness trajectory with symptoms such as episodic breathlessness. ${ }^{4}$ Identifying the point of transition to palliative care is challenging - if not impossible $e^{5}$ and increases the risk of 'prognostic paralysis' for

\section{this patient group.}

Although care coordination is rarely explicitly defined, ${ }^{7}$ it is usually described as the communication between different professionals and healthcare settings about treatment and care for appropriate delivery of healthcare services. ${ }^{8}$ Effective coordination of care should facilitate access to services and support that is consistent with the patient's needs and level of understanding. ${ }^{9,10}$ For individuals with palliative care needs irrespective of diagnosis, successful coordination should ensure access to palliative care regardless of whether this is delivered by the primary healthcare or specialist palliative care team, if this is what patients prefer. To enhance care coordination, the Gold Standards Framework for England and Wales highlights the importance of coordinators in each primary care practice, ${ }^{11}$ and

\footnotetext{
* Corresponding author: Dr Eleni Epiphaniou, Centre for Primary Care and Public Health, Blizard Institute, Barts and The London School of Medicine and Dentistry, Yvonne Carter Building, 58 Turner Street, London E1 2AB, UK. E-mail: e.epiphaniou@qmul.ac.uk
} 
the Department of Health (DoH) argues that a care coordinator is more appropriate for people who experience an increased number of unplanned emergency admissions. ${ }^{12}$

Our longitudinal study aimed to explore patients' experience of being in receipt of the evolving and complex process of advanced care coordination within and between primary and secondary care settings in order to inform current debates on care coordination of patients towards the end of life. We explored the processes by which end-of-life care is coordinated and managed in generalist settings and what is best practice in care coordination.

\section{Methods}

\section{Study design}

A qualitative longitudinal study was conducted, which involved indepth serial interviews with patients with lung cancer and those with advanced COPD. A longitudinal design was selected as this facilitates the exploration of dynamic needs and experiences, and the relationship built up over time enables a discussion of sensitive topics that are more difficult to approach in single interviews. ${ }^{5,13}$

\section{Recruitment}

Potentially eligible participants were recruited from the same service and were identified from three outpatient clinics of the Respiratory Department at a London teaching hospital. The hospital serves primarily the most deprived boroughs in England with life expectancies for men and women remaining worse than the England average.

Clinical staff were asked to identify patients with advanced progressive conditions assumed to be in the last year of life. Clinicians were guided by clinical criteria as detailed in the Supportive and Palliative Care Indicators Tool (SPICT) (www.spict.org.uk), ${ }^{14}$ and their own holistic clinical judgement centred on whether they would not be surprised if the patient died within a year. Patients unable to provide consent or those who were cognitively impaired, had hearing problems, had difficulty communicating in English to the extent that they could not participate in an in-depth interview conducted in English, or were younger than 18 years were excluded from the study.

The usual clinician identified approached potential participants and interested patients provided their verbal consent for the researcher to contact them. After 48 hours the researcher contacted the patient, provided more information about the project, and arranged a convenient time for interview.

\section{Data collection}

Data collection followed standard clinical and ethical practice guidelines. ${ }^{15}$ Ethical (Lothian Research Ethics Committee 10/s1102/17) and local Research and Development Trust approval was obtained (KCH10-138).

Consenting patients were interviewed by $\mathrm{EE}$, a psychologist with extensive experience and training in conducting and analysing qualitative interviews. Interviews were audio-recorded and completed at home at three different time points using a semi-structured interview schedule. The topic guide for the first and subsequent interviews focused on (1) the condition (diagnosis, prognosis, current problems, support, and support needs); (2) experiences when interacting with the NHS (professionals' coordination, experiences when visiting the clinics, being discharged from the clinics, experiences following the visit and referrals if they were well coordinated); (3) perceptions of future care (i.e. the plans for the future); and (4) perceptions of current and future care (what coordination meant for them, how it can improve, perception on whether they felt their care was coordinated, care expectations).

\section{Analysis of data}

The interviews were transcribed verbatim and imported into NVIVO 9 software where thematic analysis procedures were implemented. ${ }^{16} \mathrm{To}$ immerse herself in the data, EE initially read and re-read the transcripts and searched for meanings and patterns with regard to patients' experiences in care coordination. Notes and ideas which would be used in subsequent stages were coded. Initial codes from the data, with interview extracts as examples, were then recorded to be used later on. Codes where then organised and annotated into themes which at the end would adequately capture the contours of the coded data. As a final stage, EE re-read the entire dataset and also discussed the themes to reach a consensus with BD and CS and, following final agreement, the coding frame was applied to the entire dataset. This was to check the validity of the themes and whether they reflected the meaning of the dataset.

\section{Results}

Between October 2011 and September 2012, clinical staff purposively identified 42 patients, of whom 28 were approached and eight declined participation. The three top reasons for not participating were too many other things to deal with at that time $(n=3)$, felt they had little to say $(n=2)$, and felt they had few needs $(n=1)$. Therefore, 20 patients consented for the serial interviews which lasted between 20 and 90 minutes. Since the aim was to explore experiences of patients with lung cancer and COPD, two patients not diagnosed with these conditions were not included in this analysis.

\section{Demographic information}

The characteristics of the participants are shown in Table 1. Eleven participants were diagnosed with lung cancer and seven with COPD. Six carers participated in some or all of the serial interviews.

Of the 18 patients recruited for Time 1 (T1) interviews, 13 patients completed Time 2 (T2) interviews. Reasons for attrition were difficulty in locating the patient $(n=3)$ and death before the interview $(n=2)$. Further attrition for the Time 3 (T3) interviews was due to the difficulty in locating the patient $(n=3)$, death before the interview $(n=1)$ or patients thinking that they did not have much to add $(n=1)$. Thus, seven patients completed all three interviews.

\section{Service usage}

Based on the longitudinal data received from a standard questionnaire completed by all patients during the first and follow-up interviews, cancer patients were more likely to receive palliative care services than COPD patients, who were more likely to self-manage while also accessing pulmonary rehabilitation. Table 2 shows the combined service usage for these patients, which refers to the number of consultations patients had between October 2011 and September 2012. 
Table 1. Age, gender, main conditions, FEV1 predicted, interview numbers, and status of patients at the end of the study

\begin{tabular}{|c|c|c|c|c|c|c|c|}
\hline $\begin{array}{l}\text { Patient } \\
\text { ID }\end{array}$ & Gender & Age & Main conditions & $\begin{array}{l}\mathrm{FEV}_{1} \\
\text { predicted }\end{array}$ & $\begin{array}{l}\text { Number of } \\
\text { interviews }\end{array}$ & $\begin{array}{l}\text { Status of } \\
\text { patient at } \\
\text { end of study }\end{array}$ & Carer \\
\hline P001 & Female & 61 & Lung cancer, metastatic to adrenal glands & - & 3 & Alive & Son \\
\hline P002 & Male & 68 & Lung cancer, emphysema (severe), breathlessness & $35 \%$ & 3 & Alive & $\begin{array}{l}\text { Domestic } \\
\text { partner }\end{array}$ \\
\hline P003 & Male & 76 & Lung cancer/asbestosis, CABG & $71 \%$ & 3 & Alive & - \\
\hline P004 & Male & 82 & Lung cancer with leg metastasis, ischaemic heart disease, CABG & - & 1 & Dead & - \\
\hline P005 & Male & 54 & Lung cancer with bone metastasis & $69 \%$ & 4 & Dead & Daughter \\
\hline P006 & Male & 70 & COPD (asthma) & $17 \%$ & 3 & Alive & Wife \\
\hline P007 & Female & 90 & Lung cancer, COPD, osteoporosis, long standing back pain & $32 \%$ & 2 & Dead & - \\
\hline P008 & Male & 72 & COPD, emphysema & $22 \%$ & 3 & Alive & - \\
\hline P009 & Male & 59 & Lung cancer, with stomach, throat and bone metastasis & $77 \%$ & 1 & Dead & $\begin{array}{l}\text { Domestic } \\
\text { partner }\end{array}$ \\
\hline P010 & Male & 65 & Lung cancer, breathless on exertion & $32 \%$ & 3 & Alive & - \\
\hline P011 & Male & 69 & Lung cancer (with kidney metastases), COPD, emphysema & $67 \%$ & 2 & Dead & $\begin{array}{l}\text { Domestic } \\
\text { partner }\end{array}$ \\
\hline P012 & Male & 63 & COPD (severe) & $26 \%$ & 3 & Alive & - \\
\hline P013 & Female & 66 & COPD & $20 \%$ & 2 & Alive & - \\
\hline P014 & Female & 52 & COPD (emphysema/ bronchial bronchitis) & $28 \%$ & 1 & Alive & - \\
\hline P015 & Male & 46 & Lung cancer with brain metastasis & - & 1 & Alive & - \\
\hline P016 & Female & 64 & Lung cancer, type 2 diabetes, hyperthyroidism & $71 \%$ & 1 & Alive & - \\
\hline P017 & Female & 74 & COPD & $55 \%$ & 1 & Alive & - \\
\hline P018 & Male & 79 & COPD, chronic asthma, heart failure & $79 \%$ & 1 & Alive & - \\
\hline
\end{tabular}

$C A B G=$ coronary artery bypass graft, $C O P D=$ chronic obstructive pulmonary disease, $\mathrm{FEV}_{1}=$ forced expiratory volume in one second.

Table 2. Service usage: number of consultations between October 2011 and September 2012

\begin{tabular}{ll} 
Community services & Total \\
\hline GP at practice & 102 \\
\hline GP at home & 19 \\
\hline GP on phone & 103 \\
\hline District nurse & 3 \\
\hline Palliative care nurse & 39 \\
\hline Lung nurse & 6 \\
\hline Secondary care usage & \\
\hline Hospital admissions & 9 \\
\hline Total days in hospital & 157 \\
\hline Outpatient visits & 167 \\
\hline Day visits & 22 \\
\hline A\&E visits & 15 \\
\hline Emergency ambulance call & 9 \\
\hline &
\end{tabular}

\section{Overview}

'Timeline' was the main theme emerging from the analysis indicating participants' experiences across their illness trajectory, i.e. from diagnosis to the time of the interview. Across their illness trajectory, patients discussed their experiences with regard to the role of a keyworker (KW), a specialist nurse, or a community palliative care nurse (CPCN). The specialist nurse coordinated their care between and within hospitals and community services while the CPCN coordinated care in the community. Along with the role, monitoring and follow-up was a second emerging sub-theme. In order to aid transparency, the results are reported separately for lung cancer and COPD patients.

\section{Experiences of lung cancer patients Role of KW: coordination between and within hospital settings}

For some the KW shared the diagnosis and referred them to hospital clinicians:

"So three weeks later ... X gave me a phone call. I was in work. At first she rung my wife up ... and she rung me ... So we both went there and saw $X$, and $X$ told us that there's a, a tumour on your, in your lung ... it's affecting all your blood cells and everything else in your lung itself. We can't do nothing about it until we go and see the oncologist." (P010/LC)

The KW was also the main point of contact:

"I didn't have the number for Hospital X, it's easier for me to call the specialist nurse because she's meant to be the point of call ... she said that she'd talk to them. I think she said she'd talk to them about Hospital X and the radiotherapy." (Ca001/LC)

The KW also liaised with other professionals to hasten treatment procedures for prompt treatment services:

"So I was under the chemo because the nurse (KW) wanted me to get the chemo straightaway and so did I, I got the treatment straightaway. So then I was on the chemo for ... I 
don't know, three months, like every weekend, every Friday just ... chemo." (P015/LC)

\section{Role of KW: coordination with the services outside the hospitals}

Furthermore, the KW coordinated care with community services such as social services, the GP, or referred patients to community palliative care services.

For some patients and carers the KW requested financial support on their behalf:

"Specialist nurse filled in a form ... which automatically gave my mum a higher rate Disability Living Allowance. She said,

'You don't need to do nothing, I'm going to send it and it's going to be done, it will take a little bit of time but then it'll be there'." (Ca001/LC)

They also contacted the GP for emergencies:

"I had radio sickness and I stopped eating. I rung the nurse (KW) up to see if, you know, they could do something ... So she phoned up my doctor, told him what pills to prescribe and I went round and got the prescription and, this was on the Friday, and I took two the first day and on the Saturday I started feeling better, you know. I took three more on the Saturday and on the Sunday I had a small dinner, you know, without bringing it up." (P003/LC)

Seven patients who required palliative care were referred by the KW to community palliative care services:

"From time X (KW) put my case to them, they come ... They just talk to me, just like talk to me, find out everything is OK, you know, if I'm getting enough money from the Government and so on." (P002/LC)

\section{Role of KW: provide support}

The majority of patients with lung cancer and their carers appreciated the KW being caring and supportive:

"But she's been very good. She phones up to me or my daughter every day, which is nice, but the nurse has a bit of caring attitude. This one is very caring, you know." (P004/LC) However, one carer commented on the KW not responding to calls and thus not being supportive:

"I understand ... that our point of contact was X (KW). That is the person that deals with all the different individuals that come together as a team to look after my mum's care. But actually the reality is, when you leave a message, the KW does not get back to you, you can't contact them." (Ca001/LC)

\section{Role of CPCN: coordination of care in the community}

When referred to community palliative care services, CPCNs acted as the patients' main coordinator within the community:

"Hospice nurse X sent a fax through, she'd been to see dad and she'd talked to me and she sent a fax through to the GP to say, right, this needs to happen immediately because something, something's happened." (Ca003/LC)

"... the palliative care team came yesterday and she went back and spoke to her doctors and then got this prescription. Exactly what KW prescribed." (P011/LC)

The CPCN also prepared for the future and provided support:
"One of the ladies from Hospice X came and we talked. We did a ... you know, you have the discussions about sort of further down the line and what you might like, what you want, we had a little meeting like that." (P005/LC)

Consequently the involvement of a coordinator across their illness trajectory enabled access to hospital, community and social services. Patients and carers felt supported and appreciated the professional's role.

\section{Monitoring and follow-up}

Patients with lung cancer reported regular follow-ups:

"I had had this back scan and I go tomorrow to find out what it was, the Hospital X, what it was like. And on July 14th I go to have my scan for the cancer. See if it's gone. I see a doctor once a week, you know, and they kind of ask me how I feel and if I'm feeling better." (P003/LC)

"They're just monitoring me really. I've got Hospice X nurses come every fortnight ... and the Matron comes from up $X$ Road, my doctor comes here. She rang me on Friday, she said 'Can I come and see you?' So I said 'Yes, sure'. We just sat chatting because she can't do anything, you know." (P007/LC)

\section{Experiences of patients diagnosed with COPD}

Unlike lung cancer patients, COPD patients did not usually have access to a dedicated KW for their illness. Patients reported access to services during acute exacerbations, which were followed by a discharge back to the community. Lengthy periods between these meant scarce monitoring and follow-up after discharge. However, a small number of patients $(n=4)$ reported consistent check-ups from their GP or hospital every 6, 9, or 12 months.

\section{Acute exacerbations}

After an acute exacerbation some COPD patients are admitted as inpatients:

"You can suddenly be in an intensive care unit, boom-boom, then you can go to the right department and then you're looked after. Then you're put back at home." (Pa013)

\section{Monitoring and follow-up}

Contrary to their expectations, some patients reported vague followup from professionals in the community or from the hospital:

"There is no follow-up. I mean I get a copy of the letter and I've, I've never been asked to go to the surgery, my GP surgery, to discuss my medication or the recommendations the, the, the consultants have made, anything like that." (Pa006)

However, some reported check-ups at the hospital or GP:

"I just see him and he monitors me and tests and represcribes. I mean it's straightforward. I get on well with him." (Pa008)

Only one patient with COPD reported follow-up from community services following discharge from hospital:

"A man came to see how you're getting on as regards getting up, out of bed, bathroom, breakfast ... he said, 'Well, I don't think you need me $X$, you seem to be very independent' - same thing, words that the ladies the night 
before had said, 'You appear to be very independent'." (P018)

Most patients persevered to manage their illness on their own:

"I do everything myself, take my medication, just stay in me own house ... I've got everything here, I've got a nebuliser ... I've got oxygen, I've got all the medication, I don't need to be in hospital. 'Cos when I'm in a hospital I take my own medication." (Pa014)

Interestingly, patients with COPD who had lung cancer $(n=3)$ reported access to different services following the involvement of the KW. Access to financial services:

"I receive DLA since I met the nurse. I'm getting, I'm getting more money, which I didn't expect." (P002/LC)

Psychological support:

"So everything I've asked, I haven't asked much, but everything I've asked off of that lady, she's gone out of her way to, to help me out. She is good as gold." (P011/LC)

And support from community palliative care:

"Well they just ask me questions like how you're doing ... and 'Are your feet swollen?' Blood pressure, pulse, you know." (P007/LC)

\section{Discussion}

\section{Main findings}

For the patients with lung cancer, care coordination in secondary settings was aided by the involvement of a keyworker (KW) who functioned as the patient's main point of contact with the health and social care system, coordinated emergencies, supported communication between professionals, provided support, and referred patients to community services. In the community, care coordination was managed by the community services that provided support, liaised with clinicians in the community, and prepared patients and carers for the future. Most patients reported access to different services and regular follow-ups.

COPD patients did not usually have access to a dedicated KW for their illness. Consequently, their accounts did not usually feature a professional whose role was to provide support or facilitate coordination. Some patients experienced regular check-ups while others indicated reduced service access and few follow-ups and check-ups. During an acute exacerbation some patients reported being hospitalised to receive excellent and enhanced care coordination between hospital clinicians. However, when returning to the community, patients reported lack of proactive primary or secondary follow-up. Consequently, evidence from the current study shows that, while cancer patients have fast moving situations and highly responsive care, the recruited patients with COPD had little continuity, no forward planning, and less access to services, unless developing lung cancer. Patients diagnosed with COPD and lung cancer reported access to various services after the involvement of the KW. This perhaps strengthens the suggestion that a lung cancer diagnosis is what seems to trigger access to effective care coordination.

\section{Strengths and limitations of this study}

Our multi-perspective longitudinal qualitative study aids in understanding peoples' experiences regarding care coordination. Although the study aimed to include participants with a diversity of characteristics, our 18 participants do not fully represent patients with advanced lung cancer and advanced progressive COPD as they were recruited from three respiratory outpatient clinics from a London teaching hospital. Also, it was not possible to determine whether the differences in care provision and access were due to need or difficulties regarding equity of care. Nevertheless, differences were apparent in the experiences of this group of patients and they provide a useful insight into the differences in coordination experienced by two groups in one setting.

\section{Interpretation of findings in relation to previously published work}

Data obtained from interviewing lung cancer patients emphasise the important role of the $\mathrm{KW}$ in coordinating patient care between and within hospitals and the role of the community palliative care nurse (CPCN) in coordinating care in the community. Guidelines underline the importance of the involvement of a $\mathrm{KW}_{1}{ }^{17,18}$ and their supportive role in providing ongoing care coordination and continuity of care for adults with cancer across a number of different settings. ${ }^{19}$

In this study some COPD patients expressed less favourable experiences due to scarce follow-up and check-ups. Evidence shows limited professional contact and inadequate surveillance, with almost half of these patients reporting lack of regular check-ups either at the hospital or their GP. ${ }^{20}$ Regular follow-up of a patient's physical and mental condition is part of best practice ${ }^{21}$ and could perhaps reduce the incidence of breathlessness and, more importantly, episodic breathlessness. ${ }^{22}$ The National Institute for Health and Clinical Excellence guidance 2010 recommends regular check-ups with a system in place to get hospital assessment quickly if necessary. ${ }^{23}$ Proactive patient contact is possible; however, contact of COPD patients with general practices can be influenced by factors including the relationship with the GP, illness perceptions, and ease of access to the practice. ${ }^{24,25}$ Therefore, illness perceptions and expectations might have influenced patients in this study in contacting their general practice or outpatient department and requesting support and advice.

\section{Implications for future research, policy and practice}

The importance of involving a KW in the care of COPD patients and their families is highlighted in this study. Accordingly, it is proposed that the professional KW could facilitate a partnership between professionals from local sites, other hospitals, and the community for services to provide when needed. The role is important in enabling continuity of care and in enhancing proactive monitoring to minimise exacerbations. The importance of coordinators in each primary care practice is emphasised in the Gold Standards Framework, ${ }^{11}$ and it is argued that a care coordinator is more appropriate for people who experience an increased number of unplanned emergency admissions. ${ }^{12}$ However, a UK national survey of COPD specialist nurse services in the community found a mismatch between the services provided for patients with COPD and the existing evidence concerning effectiveness. ${ }^{26}$

Research into the effectiveness and cost-effectiveness of a KW role is required to determine whether this can make a difference to 
care. Currently, the evidence to support the effectiveness of $\mathrm{KW}$ interventions is contradictory, with some studies having ambiguous results while others show greater patient satisfaction in care and communication. ${ }^{20,27-29}$ However, there is insufficient evidence to determine the training required, ideal qualifications, and specific duties that should be performed by professionals. ${ }^{7}$

\section{Conclusions}

The role of the KW augmented the experience of care coordination within and between settings and enabled access to various services for the lung cancer patients in this study. The different experiences highlighted by patients with lung cancer and those with COPD in the community suggest the potential of this professional role to coordinate proactive care in the community for patients diagnosed with advanced COPD. Further research into the effectiveness of $\mathrm{KW}$ interventions, especially for those with non-malignant disease, is required.

\section{Handling editor Niels Chavannes \\ Statistical review Gopal Netuveli}

Acknowledgements We thank the participants for giving their time to be interviewed and describing their experiences, and clinicians from the outpatient clinics for enabling recruitment.

Conflicts of interest The authors declare that they have no conflicts of interest in relation to this article.

Contributorship BM, SAM and IJH contributed in the study conception and design. $\mathrm{CS}, \mathrm{BD}$ and $\mathrm{RH}$ helped $\mathrm{EE}$ in data interpretation. $\mathrm{EE}$ was responsible for handling of data, manuscript draft and finalization. All authors had authority over manuscript preparation, approval of final version, and the decision to submit for publication.

Funding NIHR Service Delivery and Organisation Programme. BAD was funded by BuildCARE for the duration of this project.

\section{References}

1. World Health Organization. WHO definition of palliative care. Geneva, 2008.

2. Traue DC, Ross JR. Palliative care in non-malignant diseases. J R Soc Med 2005; 98(11):503-06. http://dx.doi.org/10.1258/jrsm.98.11.503

3. Addington-Hall J. Reaching out: specialist palliative care for adults with nonmalignant disease. London: National Council for Hospices and Specialist Palliative Care Services, 1995

4. Simon ST, Bausewein C, Schldmann E, et al. Episodic breathlessness in patients with advanced disease: a systematic review. J Pain Symptom Manage 2013;45(3):561 78. http://dx.doi.org/10.1016/j.jpainsymman.2012.02.022

5. Pinnock $H$, Kendall $M$, Murray $S A$, et al. Living and dying with severe chronic obstructive pulmonary disease: multi-perspective longitudinal qualitative study. BMJ 2011;342:d142. http://dx.doi.org/10.1136/bmj.d142

6. Murray SA, Boyd K, Sheikh A. Palliative care in chronic illness. BMJ 2005;330(7492):611-12. http://dx.doi.org/10.1136/bmj.330.7492.611

7. Mason B, Epiphaniou E, Nanton V, et al. Coordination of care for individuals with advanced progressive conditions: a multi-site ethnographic and serial interview study. Br J Gen Pract 2013 (in press). http://dx.doi.org/10.3399/bjgp13X670714
8. McDonald KM, Sundaram V, Bravata DM, et al. Closing the quality gap: a critical analysis of quality improvement strategies. Volume 7: Care Coordination. 2007.

9. O'Malley AS, Cunningham PJ. Patient experiences with coordination of care: the benefit of continuity and primary care physician as referral source. J Gen Intern Med 2009;24(2):170-7. http://dx.doi.org/10.1007/s11606-008-0885-5

10. Chan WC, Nichols J. Improving the coordination of palliative care. J Med Med SCi 2011:2(11):1225-34.

11. The Gold Standards Framework (GSF). The Gold Standards Framework in primary care. GSF primary care briefing paper. 2009.

12. Department of Health. Improving care for people with long term conditions. Care coordination. https://www.gov.uk/government/uploads/system/uploads/attachment data/file/215948/dh_124050.pdf

13. Murray SA, Kendall M, Carduff $E$, et al. Use of serial qualitative interviews to understand patients' evolving experiences and needs. BMJ 2009;339:b3702. http://dx.doi.org/10.1136/bmj.b3702

14. Boyd K, Murray SA. Recognising and managing key transitions in end of life care. BMJ 2010;341:c4863. http://dx.doi.org/10.1136/bmj.c4863

15. Department of Health. Research governance framework for health and social care. 2005.

16. Braun V, Clarke V. Using thematic analysis in psychology. Qual Res Psychol 2006;3(2):77-101. http://dx.doi.org/10.1191/1478088706qp063oa

17. National Institute for Health and Clinical Excellence. Services of people with chronic obstructive pulmonary disease. 2011

18. Department of Health. Services and public safety service framework for respiratory health and wellbeing. 2009

19. National Institute for Health and Clinical Excellence. The manual for cancer services. 2004.

20. Elkington $H$, White $P$, Addington-Hall J, Higgs $R$, Edmonds $P$. The healthcare needs of COPD patients in the last year if life. Palliat Med 2005;19:485-91. http://dx.doi.org/10.1191/0269216305pm1056oa

21. Jones PW, Agusti AG. Outcomes and markers in the assessment of chronic obstructive pulmonary disease. Eur Respir J 2006;27(4):822-32. http://dx.doi.org/10.1183/09031936.06.00145104

22. Simon ST, Higginson I, Benalia H, et al. Episodes of breathlessness: types and patterns - a qualitative study exploring experiences of patients with advanced diseases. Palliat Med 2013;27(6):524-32. http://dx.doi.org/10.1177/0269216313480255

23. National Institute for Health and Clinical Excellence. Information for the public Chronic obstructive pulmonary disease. 2010.

24. Shipman C, White S, Gysels M, White P. Access to care in advanced COPD: factors that influence contact with general practice services. Prim Care Respir J 2009; 18(4):273-8. http://dx.doi.org/10.4104/pcri.2009.00013

25. White $P$, White $S$, Edmonds $P$, et al. Palliative care or end-of-life care in advanced chronic obstructive pulmonary disease: a prospective community survey. $\mathrm{Br} J \mathrm{Gen}$ Pract 2011;61(587):e362-70. http://dx.doi.org/10.3399/bjgp11X578043

26. Candy B, Taylor SJ, Ramsay J, Esmond G, Griffiths CJ, Bryar RM. Service implications from a comparison of the evidence on the effectiveness and a survey of provision in England and Wales of COPD specialist nurse services in the community. Int J Nurs Stud 2007;44(4):601-10. http://dx.doi.org/10.1016/j.jnurstu.2005.12.007

27. Han PK, Rayson D. The coordination of primary and oncology specialty care at the end of life. J Natl Cancer Inst Monogr 2010;40:31-7. http://dx.doi.org/10.1093/jncimonographs/lgq003

28. King N, Melvin J, Ashby J, Firth J. Community palliative care: role perception. $\mathrm{Br} J$ Community Nurs 2010;15(2):91-8.

29. Dean MM. End-of-life care for COPD patients. Prim Care Respir J 2008;17(1):46-50. http://dx.doi.org/10.3132/pcrj.2008.00007

Available online at http://www.thepcrj.org 